\title{
Neonatal effects of maternal magnesium sulphate in preeclampsia: a case control study
}

\author{
Karunaa Joe Sengottaian, Sheela Shivamonga Rangappa*
}

Department of Obstetrics and Gynaecology, Sri Devaraj URS Medical College, Tamaka, Kolar, Karnataka, India

Received: 29 November 2021

Revised: 01 January 2022

Accepted: 03 January 2022

\section{*Correspondence:}

Dr. Sheela Shivamonga Rangappa,

E-mail: drsrsheela@gmail.com

Copyright: ( $)$ the author(s), publisher and licensee Medip Academy. This is an open-access article distributed under the terms of the Creative Commons Attribution Non-Commercial License, which permits unrestricted non-commercial use, distribution, and reproduction in any medium, provided the original work is properly cited.

\section{ABSTRACT}

Background: Preeclampsia is a significant public health problem in developed and developing countries. It is a multiorgan system disorder, hence making it demanding to find out severity markers. ${ }^{4}$ Awareness, recognition and knowledge of risk factors of preeclampsia will assist in predicting and lessen the recurrence of preeclampsia. In severe cases of preeclampsia and in eclampsia, magnesium sulfate is an effective anticonvulsant. Aims and objectives were: to document the clinical parameters of patients with or more than 28-week gestation having preeclampsia or eclampsia receiving magnesium sulphate and patients with or more than 28-week gestation having preeclampsia but not receiving magnesium sulphate; and to compare and study the obstetric and neonatal outcomes between the groups.

Methods: A case control study was performed among patients who delivered at RLJH hospital during study period (July 2020-July 2021), subjects who were administered magnesium sulphate due to maternal conditions were taken as cases and the subjects who did not receive magnesium sulphate were taken as controls. Obstetrical and neonatal outcomes were compared between both the groups. Data was entered in Microsoft excel sheet. Unpaired t test was performed. P value less than 0.0001 was considered significant.

Results: Magnesium sulphate did not have significant effects on the neonatal and obstetrical outcome.

Conclusions: The association between magnesium sulphate administration and neonatal outcomes were studied and it concludes that the administration of magnesium sulphate for the mother didn't have significant effects on the neonatal and obstetrical outcome.

Keywords: Preeclampsia, Neonate, Magnesium sulphate, Eclampsia

\section{INTRODUCTION}

Pre-eclampsia is a multiple system disorder taking place in pregnancy and puerperium which is identified by development of hypertension of 140/90 $\mathrm{mmHg}$ and above, after $20^{\text {th }}$ week in a previously normotensive patient. ${ }^{1}$ It accounts for about $2-8 \%$ of world population and 11-29\% of Indian population. ${ }^{2}$ It accounts for nearly $18 \%$ of all maternal deaths worldwide. ${ }^{3}$ According to World Health Organization (WHO), incidence is 7 times greater in developing countries when compared to developed country.
Preeclampsia is a significant public health problem in developed and at the same time in developing countries. ${ }^{4}$ It is a multi-organ system disorder, hence making it demanding to find out severity markers. Awareness, recognition and knowledge of risk factors of preeclampsia will assist in predicting and lessen the recurrence of preeclampsia. ${ }^{12}$ In severe cases of preeclampsia and in eclampsia, magnesium sulfate administered parenterally is an effective anticonvulsant that avoids central nervous system depression in either the mother or the infant. 
Present criteria for the diagnosis of preeclampsia is the presence of de novo hypertension (blood pressure of $\geq 140 / 90 \mathrm{mmHg}$ ), with proteinuria or any other multisystem complications, with onset after the $20^{\text {th }}$ week of gestation. ${ }^{1}$ Magnesium sulfate $\left(\mathrm{MgSO}_{4} \cdot 7 \mathrm{H}_{2} \mathrm{O}\right)$ is one of the most frequently used obstetric drugs and is the first line therapy for preventing eclampsia. ${ }^{7}$ Magnesium sulfate has $8.12 \mathrm{mEq}$ per $1 \mathrm{~g}$. Parenterally administered magnesium is excreted almost totally by renal excretion, and magnesium intoxication is rare when the glomerular filtration rate is normal or very slightly decreased. Adequate urine output mostly correlates with good glomerular filtration rates. Magnesium excretion is urine flow reliant. ${ }^{8}$ So, serum creatinine levels should be measured to rule out a decreased glomerular filtration rate.

Magnesium can cross the placenta, and fetal serum magnesium levels have been shown usually to correlate with maternal serum magnesium levels. ${ }^{4}$ The use of magnesium sulphate as prophylactic anticonvulsant in severe preeclampsia and management of eclamptic seizures is well established and is proven to improve maternal outcomes ${ }^{11}$. The use of magnesium sulphate as a neuro-protective agent in preterm deliveries is also approved. So this study focuses on the neonatal effects among women receiving magnesium sulphate for maternal indications. ${ }^{6}$ Eclamptic convulsions mostly prevented or arrested by plasma magnesium levels maintained between 4 to $7 \mathrm{mEq} / \mathrm{l}, 4.8$ to $8.4 \mathrm{mg} / \mathrm{dl}$, or 2.0 to $3.5 \mathrm{mmol} / 1 .{ }^{14}$ Although laboratories interpret total magnesium levels, free or 1 ionized magnesium actively participate in suppressing neuronal d excitability. ${ }^{5}$

RLJH hospital being a tertiary care center the prevalence of preeclampsia and eclampsia is high. Magnesium sulfate is one of the most commonly used obstetric drugs and is the standard therapy for preventing eclampsia, data correlating neonatal outcomes in fetuses exposed to magnesium sulphate are lacking. This study is intended to study the neonatal effects among women receiving magnesium sulphate for maternal indications.

\section{Objectives of the study}

The aims and objectives of the study were as follows: to document the clinical parameters (patients with or more than 28-week gestation having preeclampsia or eclampsia receiving magnesium sulphate, and patients with or more than 28-week gestation having preeclampsia but not receiving magnesium sulphate); to compare the obstetric and neonatal outcomes between the above groups; and to study the association between magnesium sulphate administration and neonatal outcomes.

\section{METHODS}

\section{Source of data}

Preeclampsia and eclampsia patients delivered at RLJH hospital during the period of study.

\section{Study design \\ It was a case control study.}

\section{Study period}

The study period was from July 2020 - July 2021 .

\section{Method of collection of data}

Data collected was entered in Microsoft excel spread sheet and unpaired t test was performed.

\section{Inclusion criteria}

Group A included 23 singleton pregnancy with hypertension developed after 20 weeks of pregnancy who was administered injection $\mathrm{MgSO}_{4}$ in antepartum period or intrapartum period. Group B included 23 singleton pregnancy with hypertension developed after 20 weeks of pregnancy who have not received injection $\mathrm{MgSO}_{4}$ in present pregnancy (according to ACOG guidelines; blood pressure $(\mathrm{BP}) \geq 140 / 90 \mathrm{mmHg}$ at 2 intervals 4 hours apart with or without significant proteinuria) and severe preeclampsia (according to ACOG guidelines, BP $\geq 160 / 110$ $\mathrm{mmHg}$ and proteinuria $>5 \mathrm{gm} / 24$ hours), developing after 20 weeks of gestation, were included.

\section{Exclusion criteria}

Pregnancy less than 20 weeks of gestation; patient with coagulation disorders like idiopathic thrombocytopenia, sickle cell disease, viral hepatitis, cholestatic jaundice, acute fatty liver, malaria, and chronic hypertension.

\section{Methodology}

A cross sectional comparative study was conducted among pregnant women above 20 weeks of gestation, who were recruited from labour ward. Institutional ethics committee approval and a written informed consent was obtained from each patient before starting the study. Baseline demographic details along with pregnancy risk factors was taken into account. Blood pressure and proteinuria was estimated in all the subjects. Information on presence of nausea, vomiting, headache, urine output less than 400 $\mathrm{ml} / 24$ hours, haemogram, hypoproteinaemia, raised liver enzymes, deranged LFT, presence of haemolysis was observed and noted. Patients with preeclampsia/eclampsia receiving magnesium sulphate were included in one group (case). Patients with preeclampsia, not requiring magnesium sulphate, were included in the other group (control), fetal outcomes were studied in each group and was compared post-partum referrals.

\section{Sample size}

There are 2 groups: group A included 23 singleton pregnancy with hypertension developed after 20 weeks of pregnancy who was administered injection $\mathrm{MGSO}_{4}$ in 
antepartum period or intrapartum period group B included 23 singleton pregnancy with hypertension developed after 20 weeks of pregnancy who have not received injection $\mathrm{MGSO}_{4}$ in present pregnancy.

$n=\frac{2 s_{p}^{2}\left[z_{1-\alpha / 2}+z_{1-\beta}\right]^{2}}{\mu_{d}^{2}}$

$s_{p}^{2}=\frac{s_{1}^{2}}{s_{2}^{2}}$

Where, $s_{1}^{2}$ is the standard deviation in the first group; $s_{2}^{2}$ is the standard deviation in the second group; $\mu_{d}^{2}$ is the mean difference between the samples; $\alpha$ is significance level; and $1-\beta$ is power.

\section{RESULTS}

In the present study mean age of group A was $24.55 \pm 4.58$ and the mean age of group B was 25.25 \pm 4.44 .mean age between two groups is nearly closer together (Table 1 ).

Among the 23 participants of group A (43.5\%) were primi $(39.1 \%)$ were gravida 2 and (13\%) were gravida 3 and (4\%) were gravida 4 . Among the participants of group B $(34.8 \%)$ were primi $(34.8 \%)$ were gravida $2(21.7 \%)$ were gravida 3 and $(8.7 \%)$ were gravida 4 (Table 2 ).

Among the 23 participants of group A (52.2\%) belonged to 36 weeks to 40 weeks of gestation. Among the participants of group B $(47.8 \%)$ belonged to 36 weeks to
40 weeks of gestation. Most of the case and controls are between 36 weeks to 40 weeks of gestation (Table 3 ).

In case group most common mode of delivery was LSCS $(52.2 \%)$ and in controls most common mode of delivery was vaginal delivery $(60.9 \%)$ but there is no statistical significance (Table 4). In case group most common mode of delivery was LSCS $(52.2 \%)$ and in controls most common mode of delivery was vaginal delivery (60.9\%) but there is no statistical significance.

In the present study in the case group the mean birth weight is $2.682 \mathrm{~kg}$ and mean birth weight in the control group is $2.931 \mathrm{~kg}$ and they are comparable (Table 5).

In the present study in the case group $47.8 \%$ babies were admitted in NICU due to various reasons and $52.2 \%$ of babies in control group were admitted in NICU. P value is 0.087 which is statistically not significant. It shows that there is no significant difference between the case group and control group in terms of NICU admission (Table 6).

In the present study respiratory distress among the case group is $56.5 \%$ and in the control group is $52.2 \%$. There is no statistical significance between both the groups concerning to respiratory diseases (Table 7).

In the present study $52.2 \%$ of babies in the case group had passed meconium before birth and in the control group $39.1 \%$ of the babies had passed meconium before birth and there is no statistical significance between the groups pertaining to meconium passage before birth (Table 8).

Table 1: Comparison of age between case and controls.

\begin{tabular}{|c|c|c|c|c|}
\hline \multirow{2}{*}{ Age (years) } & \multicolumn{2}{|l|}{ Case } & \multicolumn{2}{|l|}{ Control } \\
\hline & Number & Percentage & Number & Percentage \\
\hline $18-20$ & 3 & 13.0 & 4 & 17.4 \\
\hline 21- 25 & 14 & 69.9 & 13 & 56.5 \\
\hline $26-30$ & 4 & 17.4 & 5 & 21.7 \\
\hline 31-35 & 2 & 8.7 & 1 & 4.3 \\
\hline Total & 23 & 100.0 & 23 & 100.0 \\
\hline
\end{tabular}

Table 2: Comparison of parity between case and controls.

\begin{tabular}{|lllll|}
\hline Parity & Case & & Control & \\
\hline Gravida 1 & Number & Percentage & Number & Percentage \\
\hline Gravida 2 & 10 & 43.5 & 8 & 34.8 \\
\hline Gravida 3 & 9 & 39.1 & 8 & 34.8 \\
\hline Gravida 4 & 3 & 13.0 & 5 & 21.7 \\
\hline Total & 1 & 4.3 & 2 & 8.7 \\
\hline
\end{tabular}

Table 3: Comparison of period of gestation between case and controls.

\begin{tabular}{|lllll|}
\hline Period of gestation & Case & & \multicolumn{2}{c}{ Control } \\
& Number & Percentage & Number & Percentage \\
\hline 27-30 weeks of gestation & 0 & 0 & 1 & 4.3 \\
\hline
\end{tabular}




\begin{tabular}{|lllll|}
\hline \multirow{2}{*}{ Period of gestation } & Case & & Control & \\
\hline 30 weeks $\mathbf{1}$ day-35 weeks $\mathbf{5}$ days of gestation & Number & Percentage & Number & Percentage \\
\hline 36-40 weeks of gestation & 8 & 34.8 & 7 & 30.4 \\
\hline More than 40 weeks of gestation & 12 & 52.2 & 11 & 47.8 \\
\hline Total & 3 & 13.0 & 4 & 17.4 \\
\hline
\end{tabular}

Table 4: Comparison of mode of delivery between case and controls.

\begin{tabular}{|llllll|}
\hline Mode of delivery & Case & \multicolumn{3}{c}{ Control } & P value \\
\hline LSCS & Number & Percentage & Number & Percentage & \\
\hline Vaginal delivery & 12 & 52.2 & 9 & 39.1 & 0.9 \\
\hline Total & 11 & 47.8 & 14 & 60.9 & 0.789 \\
\hline
\end{tabular}

Table 5: Comparison of birth weight between case and controls.

\begin{tabular}{|llllc|}
\hline \multirow{2}{*}{ Birth weight } & Case & & Control & \\
\hline Less than 2 $\mathbf{~ k g}$ & Number & Percentage & Number & Percentage \\
\hline $\mathbf{2 - 2 . 5 ~ k g}$ & 5 & 21.7 & 3 & 13.0 \\
\hline $\mathbf{2 . 6 - 3 ~ k g}$ & 11 & 47.8 & 8 & 34.8 \\
\hline $\mathbf{3 . 1} \mathbf{- 3 . 5} \mathbf{~ k g}$ & 3 & 13.0 & 8 & 34.8 \\
\hline More than 3.5 kg & 3 & 13.0 & 3 & 13.0 \\
\hline Total & 1 & 4.3 & 1 & 4.35 \\
\hline
\end{tabular}

Table 6: Comparison of NICU admission between case and controls.

\begin{tabular}{|lllcc|}
\hline NICU admission & Case & & Control & \\
\cline { 2 - 4 } & Number & Percentage & Number & Percentage \\
\hline Yes & 11 & 47.8 & 12 & 52.2 \\
\hline No & 12 & 52.2 & 11 & 47.8 \\
\hline Total & 23 & 100.0 & 23 & 100.0 \\
\hline
\end{tabular}

Table 7: Comparison of respiratory distress between case and controls.

\begin{tabular}{|llllll|}
\hline Respiratory distress & Case & \multicolumn{3}{c}{ Control } & P value \\
\cline { 2 - 5 } & Number & Percentage & Number & 52.2 & \\
\hline Yes & 13 & 56.5 & 12 & 47.8 & \\
\hline No & 10 & 43.5 & 11 & 100.0 & 0.088 \\
\hline Total & 23 & 100.0 & 23 & \\
\hline
\end{tabular}

Table 8: Comparison of meconium passage before birth between case and controls.

\begin{tabular}{|c|c|c|c|c|c|}
\hline \multirow{2}{*}{ Meconium passage } & \multicolumn{2}{|l|}{ Case } & \multicolumn{2}{|l|}{ Control } & \multirow{2}{*}{ P value } \\
\hline & Number & Percentage & Number & Percentage & \\
\hline Yes & 12 & 52.2 & 9 & 39.1 & \\
\hline No & 11 & 47.8 & 14 & 60.9 & \\
\hline Total & 23 & 100.0 & 23 & 100.0 & 0.789 \\
\hline
\end{tabular}

\section{DISCUSSION}

Magnesium sulphate is well accepted as the treatment for prophylaxis of preeclampsia and for management of eclampsia. $^{22}$ Maternal adverse effects are less, and safety is well known. In preterm foetuses, antenatal magnesium sulphate acts as a neuro-protective agent and is now introduced in most guidelines. ${ }^{23}$ However, systematic reviews opine that there is no evidence for administration of magnesium for neuro-protection of the term infant. Hence, the study of the neonatal effects of magnesium 
sulphate - the apparently indispensable drug for maternal benefit-formed the basis of the study. ${ }^{24}$ The administration of magnesium sulphate, hence, raises concerns not only for the doctors but also for nurses and midwives. In our study, the obstetric outcomes were comparable. Mode of delivery and birth weight remained comparable among the groups.

\section{Neonatal effects of magnesium}

NICU admission rate was $21.7 \%$, in the control group not receiving magnesium sulphate. Greenberg et al even in his study there is a high rate of NICU admission. ${ }^{25}$ Same results were identified by the same authors in two different study cohorts also. ${ }^{26}$

The rate of neonatal hypotonia was $17 \%$ in the study by Das et al. In a large retrospective cohort study by AbbasiGhanavati et al. Also, presence of neonatal hypotonia matched with the increasing neonatal magnesium levels. ${ }^{26}$ In our study neonatal hypotonia was not taken into consideration. In our study, the occurrence of respiratory distress was comparable among both the case and control groups. However, this finding is different from the study of Greenberg and Riaz et al. In his study there was higher rate of respiratory distress.
The time of meconium passage was similar among both groups. However, the slowing down effect of magnesium on the gastrointestinal system of the neonate is already established, with a study by Havranek et al reporting effects on intestinal blood flow velocity. ${ }^{21}$

\section{Relation of NICU admission rate to magnesium levels}

In our study, NICU admission rate was higher in both the groups but there was no relation to the administration of magnesium sulphate but our findings are different from Greenberg et al. He identified duration and dose dependent increase in the rate of NICU admission. ${ }^{25}$

A study by Sherwin et al had found that foetal effects due to use of magnesium sulphate can be affected by magnesium levels. Increasing maternal magnesium levels showed increased foetal complications like lower Apgar score. It was also identified that maternal and neonatal magnesium levels are correlated well. ${ }^{27}$ But a review article by Drassinower states that magnesium sulphate exposure do increase the need for neonatal resuscitation.

In our study, there was no increase in NICU admission magnesium sulphate administion, yet it is recommended to have a trained neonatologist to be present when a baby is delivering.

Table 9: Comparison of neonatal outcomes between our study and other studies.

\begin{tabular}{|llll|}
\hline Parameters & Our study (\%) & Wassie et al (\%) & Nabrean et al (\%) \\
\hline NICU admission & 47.8 & 18.4 & - \\
\hline Respiratory distress & 56.5 & 41.1 & - \\
\hline $\begin{array}{l}\text { Meconium passage before } \\
\text { birth }\end{array}$ & 52.2 & - & No significance \\
\hline Perinatal outcome & No significance & $\begin{array}{l}\text { Significant increase in perinatal } \\
\text { mortality and morbidity }\end{array}$ \\
\hline
\end{tabular}

Table 10: Comparison of neonatal outcomes like NICU admission, respiratory distress, meconium passage before birth and perinatal outcomes between our study and other studies.

\begin{tabular}{|lllll|}
\hline Parameters & $\begin{array}{l}\text { Our study } \\
(\%)\end{array}$ & Abalas et al (\%) & $\begin{array}{l}\text { Ambadkar et al } \\
(\%)\end{array}$ & Roy et al $(\%)$ \\
\hline NICU admission & 47.8 & 25.8 & 27.7 & 15.2 \\
\hline Respiratory distress & 56.5 & - & 10 & - \\
\hline $\begin{array}{l}\text { Meconium passage before } \\
\text { birth }\end{array}$ & 52.2 & - & 26 & - \\
\hline Perinatal outcome & $\begin{array}{l}\text { No } \\
\text { significance }\end{array}$ & $\begin{array}{l}\text { Significant increase } \\
\text { in perinatal morbidity }\end{array}$ & $\begin{array}{l}\text { Significant neonatal } \\
\text { morbidity }\end{array}$ & No significance \\
\hline
\end{tabular}

\section{CONCLUSION}

In the current study clinical parameters of patients with or more than 28-week gestation having preeclampsia or eclampsia receiving magnesium sulphate and patients with or more than 28-week gestation having preeclampsia but not receiving magnesium sulphate were documented obstetric and neonatal outcomes between the groups were compared. And the association between magnesium sulphate administration and neonatal outcomes were studied conclude in this study the administration of 
magnesium sulphate for the mother did not have any significant effects on the neonatal and obstetrical outcome in terms of need for NICU admission and mode of delivery.

\section{Funding: No funding sources}

Conflict of interest: None declared

Ethical approval: The study was approved by the Institutional Ethics Committee

\section{REFERENCES}

1. Sibai BM. Hypertension in pregnancy. Clinical Obstet Gynecol. Am J Obstet Gynecol. 2004;190:1520.

2. World Health Organization. Make every mother and child count. Geneva: World health report. 2005. Available at: https://www.who.int/reproductivehealth /publications/maternal_perinatal_health/9241562900/ en/. Accessed on 15 October 2021.

3. Khan KS, Wojdyla D, Say L, Gulmezoglu AM ,Van Look PF. WHO analysis of causes of maternal death: a systemic review. Lancet. 2006;367.

4. Hallak M, Berry SM, Madincea F, Romero R, Evans MI, Cotton DB. Fetal serum and amniotic fluid magnesium concentrations with maternal treatment. Obstet Gynecol. 1993;81:185-8.

5. Bain ES, Middleton PF, Crowther CA. Maternal adverse effects of different antenatal magnesium sulphate regimens for improving maternal and infant outcomes: a systematic review. BMC Pregnancy Childbirth. BioMed Central. 2013;13:195.

6. Bain E, Bubner T, Ashwood P. Implementation of a clinical practice guideline for antenatal magnesium sulphate for neuroprotection in Australia and New Zealand. Aust N Z J Obstet Gynaecol. 2013;53(1):869.

7. Pryde PG, Mittendorf R. Contemporary usage of obstetric magnesium sulfate: indication, contraindication, and relevance of dose. Obstet Gynecol. 2009;114:669-73.

8. Doyle LW, Crowther CA, Middleton P, Marret S, Rouse D . Magnesium sulphate for women at risk of preterm birth for neuroprotection of the fetus. Cochrane Database Syst Rev. 2009;1:CD004661.

9. Lyell DJ, Pullen K, Campbell L, Ching S, Druzin ML, Chitkara U, et al. Magnesium sulfate compared with nifedipine for acute tocolysis of preterm labor: a randomized controlled trial. Obstet Gynecol. 2007;110:61-7.

10. Lyell DJ, Penn A, Caughey A, Kogut E, McClellan L, Adams B, et al. Neonatal outcomes following antenatal magnesium sulfate exposure: follow up from a magnesium vs nifedipine tocolysis RCT. Am J Obstet Gynecol. 2009;201:180.

11. Greenberg MB, Penn AA, Thomas LJ, El-Sayed YY, Caughey AB, Lyell DJ. Neonatal medical admission in a term and late-preterm cohort exposed to magnesium sulfate. Am J Obstet Gynecol. 2011;204:515.
12. American College of Obstetricians and Gynecologists. Diagnosis and management of preeclampsia and eclampsia. ACOG Practice Bulletin No. 33. Obstet Gynecol. 2002;99:159-1.

13. Lucas MJ, Leveno KJ, Cunningham FG. A comparison of magnesium sulfate with phenytoin for the prevention of eclampsia. $\mathrm{N}$ Engl $\mathrm{J}$ Med. 1995;333:201-5.

14. Coetzee EJ, Dommisse J, Anthony J. A randomised controlled trial of intravenous magnesium sulphate versus placebo in the management of women with severe pre-eclampsia. $\mathrm{Br} \mathrm{J}$ Obstet Gynaecol. 1998;105:300-3.

15. Altman D, Carroli G, Duley L, Farrell B, Moodley J, Neilson J, et al. Do women with pre-eclampsia, and their babies, benefit from magnesium sulphate? The Magpie Trial: a randomised placebo-controlled trial. Lancet. 2002;359:1877-18.

16. Yilmaz Z, Yilmaz E, Kucukozkam T. Red blood cell distribution width: A simple parameter in preeclampsia. Pregnancy Hypertens. 2016;285-7.

17. Bain ES, Middleton PF, Crowther CA. Maternal adverse effects of different antenatal magnesium sulphate regimens for improving maternal and infant outcomes: a systematic review. BMC Pregnancy Childbirth. BioMed Central. 2013;13:195.

18. Bain E, Bubner T, Ashwood P. Implementation of a clinical practice guideline for antenatal magnesium sulphate for neuroprotection in Australia and New Zealand. Aust N Z J Obstet Gynaecol. 2013;53(1):869.

19. Nguyen TMN, Crowther CA, Wilkinson D. Magnesium sulphate for women at term for neuroprotection of the fetus. Cochrane Database Syst Rev. 2013;2:CD009395.

20. Drinkwater J. Magnesium sulphate for pre-eclampsia: care of the neonate. Pract Midwife. 2011;14(11):17-9.

21. Havranek T, Ashmeade TL, Afanador M et al. Effects of maternal magnesium sulfate administration on intestinal blood flow velocity in preterm neonates. Neonatology. 2011;100(1):44-9.

22. Bain ES, Middleton PF, Crowther CA. Maternal adverse effects of different antenatal magnesium sulphate regimens for improving maternal and infant outcomes: a systematic review. BMC Pregnancy Childbirth. BioMed Central. 2013;13:195.

23. Bain E, Bubner T, Ashwood P. Implementation of a clinical practice guideline for antenatal magnesium sulphate for neuro- protection in Australia and New Zealand. Aust N Z J Obstet Gynaecol. 2013;53(1):869.

24. Nguyen TM, Crowther CA, Wilkinson D, Bain E. Magnesium sulphate for women at term for neuroprotection of the fetus. Cochrane Database Syst Rev. 2013;2:CD009395.

25. Greenberg MB, Penn AA, Thomas LJ. Neonatal medical admission in a term and late-preterm cohort exposed to magne- sium sulfate. Am J Obstet Gynecol. 2011;204(6):515. 
26. Greenberg MB, Penn AA, Whitaker KR. Effect of magne- sium sulfate exposure on term neonates. J Perinatol. 2013;33(3):188-93.

27. Sherwin CM, Balch A, Campbell SC, Fredrickson J, Clark EA, Varner M, Stockmann C, Korgenski EK,
Bonkowsky JL, Spigarelli MG. Maternal magnesium sulphate exposure predicts neonatal magnesium blood concentrations. Basic Clin Pharmacol Toxicol. 2014;114(4):318-22.

Cite this article as: Sengottaian KJ, Rangappa SS. Neonatal effects of maternal magnesium sulphate in preeclampsia: a case control study. Int J Reprod Contracept Obstet Gynecol 2022;11:462-8. 